\title{
O
}

OLHARES

REVISTA DO DEPARTAMENTO DE EDUCAÇÄO - UNIFESP

\section{PERCURSO DA COMPOSIÇÃO DE UMA COLEÇÃO DE PRODUÇÕES ACADÊMICAS EM EDUCAÇÃO SOBRE FORMADOR DE FORMADORES}

\author{
CAMINO DE LA COMPOSICIÓN DE UNA COLECCIÓN DE PRODUCCIONES \\ ACADÉMICAS EN EDUCACIÓN SOBRE FORMADORES DE FORMADORES
}

HOW TO COMPOSE A COLLECTION OF ACADEMIC PRODUCTIONS IN

EDUCATION ABOUT TRAINERS OF TRAINERS

\author{
Renata Barroso de Siqueira Frauendorf \\ Faculdade de Educação - Unicamp \\ rsfrauendorf@globo.com \\ Guilherme do Val Toledo Prado \\ Faculdade de Educação - Unicamp \\ toledo@unicamp.br
}

\begin{abstract}
Resumo: Levantar o conhecimento construído em outros tempos e espaços integra tanto o percurso de investigações acadêmicas quantitativas como qualitativas, ação que se orienta nos últimos anos, quase que exclusivamente, por caminhos previamente definidos, delimitados por protocolos, pouco suscetíveis ao erro e com isso caracterizada por ser abrangente e não tendenciosa segundo Kitchenham and Charters (2007). Este artigo apresenta o percurso de composição de uma coleção de produções acadêmicas nacionais e internacionais (2013 a 2019), sobre o/a formador(a) de formadores(as) - profissional da formação continuada que forma formadores(as) em diferentes espaços. Percurso que combinou ações planejadas a inesperadas, instigou a exploração, o arriscarse a trajetórias diferentes, favorecendo a experiência semelhante ao que vive o colecionador que atribui valor afetivo aos artefatos e não valor funcional (BENJAMIN,1987). A trajetória insere-se na investigaçãoformação, intitulada até o momento: "De estrelas a constelação: uma comunidade de práticas formativas de formadoras de formadoras" que tem como principais aportes teóricos Walter Benjamin (1987, 2018); Beillerot (1998); Imbernon (2011) e revelou o quanto a variação de denominação de cargo, contexto, sujeito e atuação da formadora de formadoras impactou significativamente na busca, seleção de publicações e, consequentemente, na compreensão do papel dessa profissional no campo educacional. Como pesquisadores colecionadores, compreendemos que, ao colocar em destaque a sensibilidade do leitor, seus conhecimentos de mundo, suas possibilidades de tecer relações entre as obras, autores, contextos, experiências, lembranças e esquecimentos, esse levantamento bibliográfico torna-se mais formativo e significativo e, muito embora seja bem mais subjetivo, não é menos importante ou menos válido.
\end{abstract}

Palavras-chave: Produção acadêmica. Formador de Formador. Pesquisa Narrativa

Resumen: Levantar el conocimiento construido en otros tiempos y espacios integra tanto el recorrido de investigaciones cuantitativas como cualitativas, acción que se orienta en los últimos años, casi exclusivamente, por caminos previamente definidos, delimitados por protocolos, poco susceptibles al 
error y con ello caracterizada por ser amplia y no sesgada según Kitchenham and Charters (2007). Este artículo presenta el recorrido de composición de una colección de producciones académicas nacionales e internacionales (2013 a 2019), sobre la formadora(a) de formadores(as) - profesional de la formación continua, que forma formadores(as), en diferentes espacios. Recorrido que combinó acciones planeadas a inesperadas, instigó la exploración, el arriesgarse a trayectorias diferentes, favoreciendo la producción de conocimiento y sentimiento semejante al que vive el coleccionista que atribuye valor afectivo a los artefactos y no valor funcional (BENJAMIN,1987). La trayectoria se inserta en la investigación formación: "De estrellas a constelación: una comunidad de prácticas formativas de formadoras" que tiene como principales aportes teóricos Walter Benjamin (1987, 2018); Beillerot (1998); Imbernon (2011)y reveló cuánto la variación de denominación de cargo, contexto, sujeto y actuación de la formadora de formadoras, impactaron significativamente en la búsqueda, selección de publicaciones y, consecuentemente, en la comprensión del papel de esa profesional en el campo educativo. Como investigadores coleccionistas, comprendemos que al poner de relieve la sensibilidad del lector, sus conocimientos de mundo, sus posibilidades de tejer relaciones entre las obras, autores, contextos, experiencias, recuerdos y olvidos hacen que este estudio bibliográfico sea más formativo y significativo y aunque es mucho más subjetivo, no es menos importante, o menos válido.

\title{
Palabras clave: Producción académica. Formador de formadores. Investigación narrativa
}

\begin{abstract}
Survey the knowledge built in other times and spaces integrates both the path of quantitative and qualitative investigations, action that is guided in recent years, almost exclusively, by previously defined paths, delimited by protocols, little susceptible to error and thus characterized by being comprehensive and non-biased according to Kitchenham and Charters (2007). This article presents the route of composition of a collection of national and international academic productions (2013 to 2019), about the trainer of trainers - a continuing education professional who trains trainers in different spaces. A process that combined planned and unexpected actions, instigated exploration, the risk of different trajectories, favoring the production of knowledge and feelings like those experienced by the collector who attributes affective value to artifacts and not functional value (BENJAMIN,1987). The trajectory is part of the research-formation: "From stars to constellation: a community of formative practices of trainers of trainers" which has as main theoretical contributions Walter Benjamin (1987, 2018); Beillerot (1998); Imbernon (2011), and revealed how the variation of denomination of position, context, subject and performance of the trainer of trainers, significantly impacted the search, selection of publications and, consequently, the understanding of the role of this professional in the educational field. As collector researchers, we understand that highlighting the reader's sensibility, their knowledge of the world, their possibilities of weaving relationships among the works, authors, contexts, experiences, memories and forgetfulnesses makes this bibliographic survey more formative and meaningful, and even though it is much more subjective, it is not less important, or less valid.
\end{abstract}

Keywords: Academic production. Trainer of Trainers. Narrative Inquiry

\section{Introdução}

\begin{abstract}
"Não existe pesquisa sem leitura. Pois nenhum tema é radicalmente novo e nenhum pesquisador pode pretender avançar sem o capital dos conhecimentos adquiridos em determinada área."
\end{abstract}

Jean Claude Kaufmann

A tarefa do homem que escava a fim de se aproximar do passado soterrado (BENJAMIN, 1987) é semelhante à do(a) pesquisador(a) que, no decorrer de sua formação acadêmica, levanta o conhecimento produzido em determinada área, seja relacionado ao foco da investigação, à temática ou a conceitos que pretende discutir e/ou ganhar mais 
conhecimento. A linha invisível que os une, numa visão benjaminiana, é a perspectiva da memória e experiência, compreendendo memória como meio onde se deu a experiência vivida e que, ao ser escavada e trazida à tona pelo homem, explode em fragmentos, lampejos, renovando o velho mundo. Nesse movimento, a experiência, outrora soterrada, ganha contornos outros, pois não se refere apenas a um passado que se quer apagar, e sim a um passado que se articula ao presente e traz possibilidades de futuro. Movimento que também é vivido durante o processo de produção de conhecimento que compõe a pesquisa, pois nem tudo que faz parte desse processo está na superfície, é explícito ou mesmo desejável, o que requer do pesquisador uma exploração mais cuidadosa, atenta, porém não menos sensível.

A tarefa, nada trivial, de levantar o conhecimento produzido em outros tempos e espaços faz parte tanto do percurso de pesquisas quantitativas como de pesquisas qualitativas, não importando a metodologia ou abordagem escolhida. Uma tarefa que pode se orientar, exclusivamente, por caminhos conhecidos previamente, definidos por protocolos pouco suscetíveis ao erro e, com isso, caracterizada por ser abrangente e não tendenciosa segundo Kitchenham and Charters (2007); ou uma tarefa que pode combinar o planejado ao inesperado e que, provavelmente, será mais atrativa a pesquisadores que não temem se perder no labirinto, assim como a criança que explora, cria caminhos diferentes, produz conhecimento e, ao contrário dos temerosos, encontra prazer de estar no labirinto, como afirma Jean Marie Gagnebin (2013). De um modo ou de outro, a ação de escavar, desenterrar, vasculhar, localizar, ler diferentes fontes de consultas, para então selecioná-las, descartá-las, organizá-las, registrá-las, estará sempre presente no cotidiano do(a) pesquisador(a), porém apenas para o colecionador(a)pesquisador(a) somam-se a essas ações "[...] uma relação com as coisas que não põe em destaque o seu valor funcional ou utilitário, a sua serventia, mas que as estuda e as ama como palco, como o cenário de seu destino." (BENJAMIN,1987, p.228)

Neste artigo pretende-se não só indicar os achados acerca da produção referente ao profissional que atua na formação continuada conhecido por formador de formadores, como também dar a conhecer o percurso trilhado pela colecionadora-pesquisadora/primeira autora ao revolver camadas mais profundas nesse ato de escavar os bancos de dados e não temer perder-se no labirinto. O estudo faz parte da investigaçãoformação ${ }^{1}$ (BRAGANÇA, 2009) de doutorado intitulada: "De estrelas a constelação: uma comunidade de práticas formativas de formadoras de formadoras", em andamento, que tem como ponto de partida a dissertação de

\footnotetext{
1 As palavras unidas têm uma razão de ser. Ao deixá-las conectadas buscamos provocar no leitor uma pluralidade de sentidos possíveis de acordo com BRAGANÇA (2009).
} 
mestrado intitulada: "A voz de uma professora-formadora que se inventa e reinventa a partir da/com/na escola" (FRAUENDORF, 2016).Tratam-se de duas pesquisas qualitativas sobre a ação do(a) formador(a) de formadores(as) para programas de formação continuada, nas quais a metodologia narrativa de investigação (PRADO et al, 2015) em diálogo com aportes teóricos de Walter Benjamin (1987, 2018); Beillerot (1998) e Imbernon (2011) constituem-se o marco teórico metodológico das produções, muito embora não haja intenção em enquadrar e/ou limitar o tema de estudo em questão a somente esses referenciais teóricos. Optamos por narrar esse exercício de escavar alguns bancos de dados e repositórios casado ao de rememorar as experiências que foram nos constituindo como sujeitos históricos seja ao ler as produções sobre esse(a) profissional da educação - especificamente do sujeito que atua em programas de formação continuada fruto de parceria público-privada em escolas, centros de formação, secretarias de educação, diretorias ou regionais de ensino, responsável por desenvolver, principalmente, a formação continuada de gestores, equipes técnicas - seja ao relacionar essas leituras ao vivido por nós em outros tempos e espaços.

A escolha por essa forma de comunicar o processo realizado se justifica tanto pelo desejo em ser coerente com a ideia e epistemologia de se fazer ciência numa perspectiva outra, menos normativa, menos cartesiana, porém com o mesmo rigor, como pelo desejo de apresentar o processo de formação e amadurecimento de ser investigador(a) no limiar ${ }^{2}$ entre uma pesquisa de mestrado e de doutorado.

$\mathrm{Na}$ modernidade tardia (GALZERANI, 2008) temos sido convocados, quase intimados, a matematizar o mundo como sinal de progresso, modo compreendido por muitos como única via de produzir conhecimento. Nossa proposta, neste estudo, é narrar uma forma outra de se relacionar com o conhecimento sobre o que vem sendo publicado e depositado nos bancos de dados, para além de apenas responder a perguntas previamente formuladas que tendem a restringir e, de certa forma, engessar as buscas feitas pelo(a) pesquisador(a). Um jeito de pensar e familiarizar-se com o conjunto de conhecimentos disponível de determinada área, que aposta na razão e percepção do "leitorpesquisador" que, ao percorrer um conjunto de palavras, ideias, é capaz de costurar relações entre os textos, os contextos e os sujeitos, as experiências, estejam essas explícitas ou escondidas; um "leitorpesquisador" que faz uso da tecnologia como o trabalhador faz da enxada e que, por essa razão, não teme voltar sempre ao mesmo fato, espalhá-lo como se "espalha a terra, revolvê-lo como se revolve o solo. Pois "fatos" [dados] nada são além de camadas que apenas à exploração mais

\footnotetext{
${ }^{2}$ Limiar para Benjamin: "O limiar (Schwelle) deve ser rigorosamente diferenciado de fronteira (Grenze). O limiar é uma zona. Mudança, transição, fluxo estão contidos na palavra schwellen [inchar, intumecer], e a etimologia não deve negligenciar estes significados" (BENJAMIN, 2018, p. 816).
} 
cuidadosa entregam aquilo que recompensa a escavação (BENJAMIN, 1987, p.239)." Uma proposta arriscada, não há dúvida!

\title{
Escavar e rememorar
}

"O formador de formador - o que já se sabe sobre esse profissional?

\begin{abstract}
Essa pergunta durante o processo de auto investigação realizado no mestrado me angustiou bastante, porque atinei que essa definição não era precisa e que havia pouca literatura sobre esse tema. Isso gerou, naquele momento, uma crise de identidade profissional, por perceber que não era ainda uma atividade socialmente reconhecida. Comecei a pensar nas tantas vezes que me perguntam o que faço e, diante da minha resposta, "sou formadora de formadores", recebo a pergunta: "certo, mas o que você faz?". Ou quando começo a explicar, e em pouco tempo eu noto que o meu ouvinte já está com o pensamento a léguas de distância. Ou, ainda, quando tenho que preencher um formulário e no campo profissão fico algum tempo refletindo sobre o que devo escrever (hoje em dia resolvi meu dilema e escrevo professora. Porque isso eu sou, e sempre serei!). Penso que toda essa confusão e falta de clareza vêm coladas a transformações sofridas pela concepção de formação continuada, e as diferentes denominações que esse profissional recebe: assessor, formador, consultor, supervisor, professor-formador, orientador. Claro que não se trata de uma simples variação de nomes, mas de ações bem específicas que mudam conforme o programa, o contexto, a condição de produção, o processo de formação vivido pelos sujeitos da formação, entre outras variáveis..." (Registro feito em Comunidade Prática de Formadores de formador publicado em 19/02/2019³)
\end{abstract}

A nossa inquietação atual situada na ideia: há avanços em relação ao que se sabe sobre o formador de formador? encontra na narrativa "O formador de formador - o que já se sabe sobre esse profissional?" pistas que nos ajudam a lembrar e ressignificar o passado por reapresentar muitas das dificuldades vivenciadas pela primeira autora no processo de produção de conhecimento no decorrer da investigação de mestrado sobre o formador de formadores, justamente pela variação de nomes que se referem a esse profissional. Também porque essa denominação aparece para diferentes ações, contextos e sujeitos. Esse primeiro levantamento, realizado no ano de 2014, teve como palavras-chaves: formador de formador; formação de formador. Apoiou-se basicamente no que foi encontrado nos bancos de dados do Google Acadêmico e na Biblioteca Digital da Unicamp. Dificuldade também apontada pela pesquisadora Vaillant (2003) ao realizar um estudo do estado da arte no campo da formação de formadores na América Latina e no Caribe no período de 1990-2013. A autora revela que apenas cinco publicações eram voltadas ao eixo formador de formadores, num total de oitenta artigos e livros publicados no período e analisados por ela. Aqui vale a ressalva de que nesse levantamento, realizado por Vaillant, não há uma referência explícita sobre o formador de

\footnotetext{
${ }^{3}$ A Comunidade Prática de Formadores de Formador é um grupo privado em rede social, criado e administrado pela primeira autora do artigo, que integra a pesquisa de doutorado. Constitui-se num dispositivo para viabilizar e incentivar a partilha de narrativas escritas de formadores de formador (FRAUENDORF e PRADO, 2021).
} 
formadores que atua em programas de formação continuada com técnicos em educação e coordenadores pedagógicos.

Ainda nesse movimento de escavar o solo, espalhar a terra e revolvê-la, Frauendorf (2016) indica que no período de 2006 a 2014, no campo da formação de formadores, foram publicadas três produções relacionadas a esse eixo pelo Grupo de Estudos e Pesquisa em Educação Continuada - GEPEC - FE - Unicamp, sendo duas dissertações (SOLIGO, 2007; PROENÇA, 2014) e uma tese de doutorado (PIERINI, 2014) que abordam o perfil, as competências e os saberes necessários a esses profissionais. Acreditamos que no processo de leitura e estudo dos conhecimentos produzidos em certa área é fundamental não só olhar para as produções acadêmicas realizadas em diferentes grupos de pesquisa e instituições externas, bem como voltar o olhar e a leitura para a literatura produzida pelo grupo de pesquisa a que o pesquisador é vinculado, a fim de conhecer e considerar o processo de conhecimento construído por investigadores outros, dentro da temática/objeto de estudo pretendido, alinhado a um mesmo princípio teórico metodológico, ainda que respeitadas as singularidades de cada pesquisador(a) .

Por fim, nesse levantamento original, também foram encontradas as dissertações de Gouveia (2012) e Gastaldi (2012) vinculadas à Pontifícia Universidade Católica de São PauloPUC/SP. Em "Formação dos coordenadores pedagógicos em Boa Vista do Tupim/BA: uma experiência colaborativa, o fio por trás das missangas”, Gouveia (2012) analisou a constituição do papel formador de coordenadores pedagógicos em escolas do Ensino Fundamental I. Gastaldi, em "Formação continuada na Educação Infantil: possibilidades e desafios na perspectiva do formador" (2012), refletiu sobre os processos formativos relativos à inclusão do formador de formador responsável pela formação do coordenador, diretor, num programa de formação continuada colaborativo na rede pública de um município da região Sul do país.

Para expor os achados dessa primeira coleção, Frauendorf (2016, p. 66) organizou um quadro intitulado: "Panorama atual da variação de denominação de cargo, contexto de formação, sujeito da formação e atuação do formador de formador no ano de 2014", tomando como referência as contribuições e produções que mais se aproximavam do recorte: formador de formador; programas de formação continuada e que dialogavam com a ideia defendida por Imbernon (2011) de que este profissional deverá ter o papel de amigo crítico, aquele que se coloca no lugar de parceiro que encoraja o próprio sujeito a encontrar pistas e soluções para o que necessita. 
Quadro 1: Panorama atual da variação de denominação de cargo, contexto de formação, sujeito da formação e atuação do formador de formador - 2014

\begin{tabular}{|c|c|c|c|c|}
\hline & Cargo & $\begin{array}{l}\text { Contexto de } \\
\text { atuação }\end{array}$ & $\begin{array}{l}\text { Sujeito da } \\
\text { formação }\end{array}$ & Ação \\
\hline \multirow{6}{*}{ 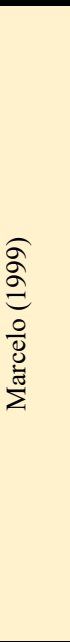 } & $\begin{array}{l}\text { Docente de crian- } \\
\text { ças, jovens e adultos }\end{array}$ & $\begin{array}{l}\text { Escola e } \\
\text { universidade }\end{array}$ & $\begin{array}{l}\text { Alunos e } \\
\text { professores }\end{array}$ & Próprias do professor \\
\hline & $\begin{array}{l}\text { Professor } \\
\text { universitário }\end{array}$ & Universidade & $\begin{array}{l}\text { Alunos uni- } \\
\text { versitários }\end{array}$ & $\begin{array}{l}\text { Formar professores de Educação } \\
\text { Infantil, Ensinos Fundamental e Médio } \\
\text { e disciplinas específicas }\end{array}$ \\
\hline & $\begin{array}{l}\text { Professor } \\
\text { universitário - } \\
\text { tutores da prática }\end{array}$ & Universidade & $\begin{array}{l}\text { Professores } \\
\text { iniciantes }\end{array}$ & $\begin{array}{l}\text { Assessorar e supervisionar professores } \\
\text { em formação durante estágios }\end{array}$ \\
\hline & $\begin{array}{l}\text { Professor universi- } \\
\text { tário - orientador }\end{array}$ & Universidade & $\begin{array}{l}\text { Professores } \\
\text { iniciante }\end{array}$ & $\begin{array}{l}\text { Assessorar e supervisionar professores } \\
\text { iniciantes, considerando o contexto } \\
\text { articulado a suas práticas }\end{array}$ \\
\hline & $\begin{array}{l}\text { Assessores de } \\
\text { formação - profis- } \\
\text { sionais de ensino } \\
\end{array}$ & $\begin{array}{l}\text { Centros de } \\
\text { formação }\end{array}$ & $\begin{array}{l}\text { Professores em } \\
\text { geral }\end{array}$ & $\begin{array}{l}\text { Responsável pelo planejamento, desen- } \\
\text { volvimento e evolução da formação dos } \\
\text { professores. }\end{array}$ \\
\hline & $\begin{array}{l}\text { Professores (com } \\
\text { certa experiência } \\
\text { profissional) }\end{array}$ & $\begin{array}{l}\text { Educação } \\
\text { não formal }\end{array}$ & $\begin{array}{l}\text { Professores em } \\
\text { geral }\end{array}$ & $\begin{array}{l}\text { Realizar atividades e ações de formação a } \\
\text { fim de capacitar os formadores tanto em } \\
\text { relação ao conhecimento do objeto a ser } \\
\text { ensinado como da competência } \\
\text { pedagógica. }\end{array}$ \\
\hline 承 & $\begin{array}{l}\text { Coordenador } \\
\text { Pedagógico }\end{array}$ & Escola & $\begin{array}{l}\text { Equipe de } \\
\text { professores }\end{array}$ & $\begin{array}{l}\text { Promover um ambiente de troca e tomada } \\
\text { de consciência, abrindo mão de uma } \\
\text { postura de especialista que determine o } \\
\text { que os professores devem fazer (p.36). }\end{array}$ \\
\hline 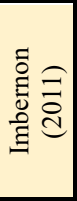 & $\begin{array}{l}\text { Assessor de } \\
\text { formação } \\
\text { permanente }\end{array}$ & $\begin{array}{l}\text { Centros de } \\
\text { formação, } \\
\text { escolas, } \\
\text { secretarias }\end{array}$ & $\begin{array}{l}\text { Profissionais } \\
\text { da educação }\end{array}$ & $\begin{array}{l}\text { Assessoria pedagógica, planejamento de } \\
\text { tarefas formativas, assessoria a escolas, } \\
\text { trabalhos de gestão e administração da } \\
\text { formação, além de assumir } \\
\text { responsabilidades na equipe pedagógica } \\
\text { (p.93). }\end{array}$ \\
\hline 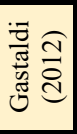 & $\begin{array}{l}\text { Técnico da } \\
\text { Secretaria da rede } \\
\text { municipal }\end{array}$ & $\begin{array}{l}\text { Centros de } \\
\text { formação, } \\
\text { escolas, } \\
\text { secretarias }\end{array}$ & $\begin{array}{l}\text { Professores, } \\
\text { coordenadores, } \\
\text { diretores da } \\
\text { rede municipal }\end{array}$ & $\begin{array}{l}\text { Realiza supervisões na instituição, organiza } \\
\text { e desenvolve encontros de formação } \\
\text { permanente, produção de documentação, } \\
\text { como diretrizes e registros (p.40) }\end{array}$ \\
\hline 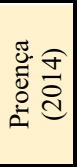 & $\begin{array}{l}\text { Supervisora da } \\
\text { prática pedagógica }\end{array}$ & $\begin{array}{l}\text { Sistema } \\
\text { municipal } \\
\text { de Ensino }\end{array}$ & $\begin{array}{l}\text { Profissionais da } \\
\text { rede municipal }\end{array}$ & $\begin{array}{l}\text { Promover uma atitude de mediação no } \\
\text { contexto escolar que possa favorecer o } \\
\text { processo reflexivo destes profissionais, } \\
\text { considerando as condições do vivido e } \\
\text { seus conflitos (p.94) }\end{array}$ \\
\hline
\end{tabular}

A falta de pesquisas sobre o ofício do(a) formador(a) de formadores(as) que atua fora da universidade parece estar mais relacionada à ausência de uma política pública de formação de formadores(as) do que por ser um tema de pouca relevância no cenário educacional, uma vez que é uma figura presente nesse cenário desde os anos 70. Na prática, os(as) formadores(as) são profissionais - professor(a), coordenador(a) pedagógico(a) - que por alguma razão se sobressaíram em seu saber-fazer-pedagógico, como diz Perrenoud (1997, p.199) e que, por isso, são convidados, algumas vezes convocados, a assumir a formação de seus próprios colegas.

Vaillant $(2013, p .8)$ ainda afirma que

As políticas e reformas educativas modernas exigem um docente ideal que, na realidade, não existe. Ainda que na formulação de políticas se evoque o docente ideal, em sua aplicação não se adotam as medidas para criá-lo. A mudança educativa continua sendo percebida como um esforço rápido e curto, e não como um processo de longo prazo. 
Outra dificuldade para encontrar estudos e literatura sobre o profissional, apontada por Marcelo Garcia (1999, p. 1-2), diz respeito a não definição do que se entende por formador. O autor identifica seis possibilidades de definição em que se altera desde a nomenclatura, os contextos de atuação, os sujeitos de formação e as principais ações. No quadro 1 percebemos que a ideia do(a) formador(a) de formadores(as) que atua em programas de formação continuada em escolas, centros de formação, secretarias de educação, diretorias ou regionais de ensino, responsável por desenvolver, principalmente, a formação continuada de gestores(as), equipes técnicas aparece já em alguns estudos como em: Carlos Marcelo Garcia (1999) quando faz referência especificamente ao(a) assessor(a) de formação que atua em centros de formação, porém para o público exclusivo de professores(as); Imbernon (2011) ao referir-se ao(a) assessor(a) de formação permanente que atua em centros de formação, escolas e secretarias com diferentes profissionais de educação; Gastaldi (2012) ao focar os estudos no(a) técnico(a) em educação, que está centrado na secretaria de educação e atua não só com professores(as), mas também coordenadores(as) e diretores(as) e, por fim, Proença (2014) ao abordar o supervisor pedagógico como profissional que desempenha ações formativas em determinada rede de ensino.

Passados seis anos do estudo em questão o que mudou nessa realidade referente ao conhecimento que se tem sobre esse(a) profissional? No contexto brasileiro o(a) profissional que atua em programas de formação continuada nas redes públicas, em parceria público-privada, tem uma dimensão de trabalho diferente do(a) formador(a) de formadores(as) que atua nas universidades e daqueles que são enunciados na literatura da área até o momento? Essas são novas inquietações que nos indicam direções possíveis a seguir, assim como a bússola e a razão contribuíam para navegantes se orientarem e se deslocarem, diferentemente de se configurarem em perguntas que engaiolem o nosso fazer.

A experiência vivida pela pesquisadora ao realizar esse levantamento de produções e organização de informações possibilitou muitos aprendizados como podemos observar no fragmento da narrativa sobre a sistematização citada.

\footnotetext{
....a partir das produções escritas que encontrei, organizei um quadro, em que uno as informações de diferentes pesquisadores sobre as denominações, ações e contextos de atuação desse profissional.

$\mathrm{Na}$ época lembro que essa sistematização me ajudou muito a me encontrar [como formadora de formadores], mesmo que parcialmente. Entendo que também poderá ajudar outros formadores a se reconhecerem em algum ou alguns dos cargos, ou incluir outros que aqui não apareceram, ou não! (Registro feito em Comunidade Prática de Formadores de formador publicado em 19/02/2019)
} 
Podemos depreender que a pesquisadora revela não somente a compreensão do seu tema de pesquisa, como também que o colecionado no processo investigativo favoreceu o desenvolvimento de sua atuação em seu campo profissional.

\section{“Desempacotando" bancos de dados e repositórios: velhos novos caminhos para conhecer o "formador de formadores".}

[...] colecionar e ler são gestos derivados um do outro, não à toa a raiz etimológica de coleção (collectio) deriva de legere, que, originariamente, remetia às ideias de colher, escolher, recolher. Três verbos que dizem tanto da prática exercida por um leitor, quanto do gesto físico do próprio colecionador: ambos colhem palavras e objetos, tirando-os da dispersão. (Bruna Ferraz)

Conforme já narrado, todo esse processo de selecionar e armazenar as produções acadêmicas sobre formador(a) de formadores(as), realizado em 2014, foi base da coleção que foi alimentada durante os anos de 2019 e 2020, no contexto de um programa de doutorado. Todo(a) colecionador(a) que se preze aprecia expor a sua coleção, porém a exposição dos objetos só ganha sentido se também puder contar como conseguiu tal artefato, onde e quando se deu a conquista, justamente porque ao narrar como funda e alimenta a coleção, o(a) colecionador(a) traz em sua essência as memórias que tangenciaram a conquista do objeto em si, uma vez que todo artefato é singular e guarda uma história (BENJAMIN, 1987). O ato de unir as peças, em nosso caso específico as produções acadêmicas, nos faz, como leitores-colecionadores-pesquisadores, reviver e ressignificar fragmentos de experiência porque, ao colocá-las lado a lado, ganham uma nova razão de ser. Para essa nova caminhada já trazíamos na bagagem a ideia de formador(a) de formadores(as) como um assessor(a) de formação permanente, enraizado(a) na escola, que desempenha o(a) papel de amigo(a) crítico(a) que, no lugar de prescrever soluções comuns a todos, oferece pistas e possibilidades na resolução de dificuldades e enfrentamento de obstáculos, seja na instituição, seja em rede de ensino. No entanto, também carregávamos algumas inquietações sobre o quanto essa ideia sobre a atuação do(a) formador(a) de formadores(as) se mantinha nos dias de hoje, uma vez que há uma tendência ao retorno de uma racionalidade técnica nesse campo (IMBERNON, 2011), bem como maior presença de estudos específicos sobre a sua atuação fora da universidade e para além dos docentes.

Ao perseguir preciosidades para essa coleção de produções acadêmicas nos questionávamos: "Por que ainda se fala tão pouco desse profissional? Por qual motivo sua atuação parece ser desinteressante a quem pensa política de formação continuada? A razão da ausência de investigações, estudos ou mesmo interesse seria pelo fato de ser considerada uma atividade fácil e natural, assim como ainda é visto por muitos o trabalho da professora, 
como problematizam Ferry (1990) e Novoa (2002)? Ou o motivo poderia ser atribuído ao fato de se tratar de um objeto de estudo e investigação difuso como indica Beillerot (1998)? Questionamentos esses sobre os quais encontramos indícios de respostas na literatura mais recente sobre o(a) formador(a) de formadores(as) como em Samia (2016); Gonzales (2018); Estepa e Gallego-Dominguez (2018); Ferreira (2018); Borges (2019); Mello (2019), principalmente.

A seguir mostramos a nossa coleção atual - as alterações do panorama estão marcadas pela cor azul - para, na sequência, partilhar como fomos "desempacotando as caixas de papelão, trazendo à luz do dia" [...] documentos que adormeciam na escuridão fria de repositórios e bancos de dados como discursa o(a) colecionador(a) ao desempacotar a biblioteca, em Imagens do Pensamento de Walter Benjamin (1987, p.227).

Quadro 2: Panorama atual da variação de denominação de cargo, contexto de formação, sujeito da formação e atuação do formador de formador (2020)

\begin{tabular}{|c|c|c|c|c|}
\hline & Cargo & $\begin{array}{l}\text { Contexto de } \\
\text { atuação }\end{array}$ & Sujeito da formação & Ação \\
\hline 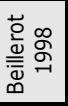 & $\begin{array}{l}\text { Formador de } \\
\text { formador }\end{array}$ & $\begin{array}{l}\text { Centros de } \\
\text { formação, } \\
\text { instituições } \\
\text { educativas }\end{array}$ & $\begin{array}{l}\text { Professores, instrutor, } \\
\text { animador, formador de } \\
\text { formadores }\end{array}$ & $\begin{array}{l}\text { Formar novos formadores; aperfeiçoar, atualizar } \\
\text { formadores em exercício. }\end{array}$ \\
\hline \multirow{6}{*}{ 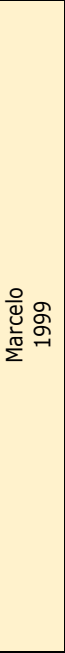 } & $\begin{array}{l}\text { Docente de } \\
\text { crianças, } \\
\text { jovens e } \\
\text { adultos } \\
\end{array}$ & $\begin{array}{l}\text { Escola e } \\
\text { universidade }\end{array}$ & Alunos e professores & Próprias do professor \\
\hline & $\begin{array}{l}\text { Professor } \\
\text { universitário }\end{array}$ & Universidade & Alunos universitários & $\begin{array}{l}\text { Formar professores de Educação Infantil, Ensinos } \\
\text { Fundamental e Médio e disciplinas específicas. }\end{array}$ \\
\hline & $\begin{array}{l}\text { Professor } \\
\text { universitário - } \\
\text { tutores da } \\
\text { prática }\end{array}$ & Universidade & Professores iniciantes & $\begin{array}{l}\text { Assessorar e supervisionar professores em } \\
\text { formação durante estágios. }\end{array}$ \\
\hline & $\begin{array}{l}\text { Professor } \\
\text { universitário - } \\
\text { orientador }\end{array}$ & Universidade & Professores iniciantes & $\begin{array}{l}\text { Assessorar e supervisionar professores iniciantes, } \\
\text { considerando o contexto articulado a suas } \\
\text { práticas. }\end{array}$ \\
\hline & $\begin{array}{l}\text { Assessores de } \\
\text { formação - } \\
\text { profissionais } \\
\text { de ensino }\end{array}$ & $\begin{array}{l}\text { Centros de } \\
\text { formação }\end{array}$ & Professores em geral & $\begin{array}{l}\text { Ser responsável pelo planejamento, } \\
\text { desenvolvimento e evolução da formação dos } \\
\text { professores. }\end{array}$ \\
\hline & $\begin{array}{l}\text { Professores } \\
\text { (com certa } \\
\text { experiência } \\
\text { profissional) }\end{array}$ & $\begin{array}{l}\text { Educação } \\
\text { não formal }\end{array}$ & Professores em geral & $\begin{array}{l}\text { Realizar atividades e ações de formação a fim de } \\
\text { capacitar os formadores tanto em relação ao } \\
\text { conhecimento do objeto a ser ensinado como da } \\
\text { competência pedagógica. }\end{array}$ \\
\hline 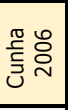 & $\begin{array}{l}\text { Coordenador } \\
\text { Pedagógico }\end{array}$ & Escola & Equipe de professores & $\begin{array}{l}\text { Promover um ambiente de troca e tomada de } \\
\text { consciência, abrindo mão de uma postura de } \\
\text { especialista que determine o que os professores } \\
\text { devem fazer (p.36). }\end{array}$ \\
\hline 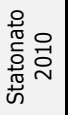 & $\begin{array}{l}\text { Professor } \\
\text { Coordenador } \\
\text { de Oficina } \\
\text { Pedagógica }\end{array}$ & $\begin{array}{l}\text { Oficina } \\
\text { Pedagógica } \\
\text { - Diretorias } \\
\text { de Ensino }\end{array}$ & Professores Coordenadores & $\begin{array}{l}\text { Realizar ações de formação junto aos } \\
\text { Professores- Coordenadores, responsável por } \\
\text { acompanhar e implementar Programa Ler e } \\
\text { Escrever }\end{array}$ \\
\hline 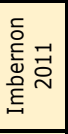 & $\begin{array}{l}\text { Assessor de } \\
\text { formação } \\
\text { permanente }\end{array}$ & $\begin{array}{l}\text { Centros de } \\
\text { formação, } \\
\text { escolas, } \\
\text { secretarias }\end{array}$ & Profissionais da educação & $\begin{array}{l}\text { "Realizar assessoria pedagógica, planejamento } \\
\text { de tarefas formativas, assessoria a escolas, } \\
\text { trabalhos de gestão e administração da } \\
\text { formação, além de assumir responsabilidades na } \\
\text { equipe pedagógica (p.93)". }\end{array}$ \\
\hline 意 & $\begin{array}{l}\text { Técnico da } \\
\text { Secretaria da } \\
\text { rede municipal } \\
\text { - Ed. Infantil }\end{array}$ & $\begin{array}{l}\text { Centros de } \\
\text { formação, } \\
\text { escolas, } \\
\text { secretarias } \\
\text { municipais } \\
\text { de educação } \\
\end{array}$ & $\begin{array}{l}\text { Professores, } \\
\text { coordenadores, diretores } \\
\text { de Ed. Infantil da rede } \\
\text { municipal }\end{array}$ & $\begin{array}{l}\text { "Realizar supervisões na instituição, organizar e } \\
\text { desenvolver encontros de formação permanente, } \\
\text { produção de documentação, como diretrizes e } \\
\text { registros (p.40)" }\end{array}$ \\
\hline 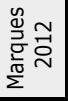 & $\begin{array}{l}\text { Assessor } \\
\text { técnico } \\
\text { pedagógico }\end{array}$ & Escolas & diretor & $\begin{array}{l}\text { Apoiar o diretor, especificamente em áreas que } \\
\text { esse não domina. }\end{array}$ \\
\hline 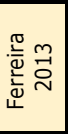 & $\begin{array}{l}\text { Técnico de } \\
\text { Ação Educativa }\end{array}$ & $\begin{array}{l}\text { Centro de } \\
\text { formação } \\
\text { profissional }\end{array}$ & $\begin{array}{l}\text { Adultos com interesse pela } \\
\text { área dos Serviços de Apoio } \\
\text { a Crianças e Jovens, } \\
\text { profissionais da área da } \\
\text { educação }\end{array}$ & $\begin{array}{l}\text { Formar adultos, profissionais da educação para } \\
\text { atuar em centros infantis que atendem crianças } \\
\text { até } 6 \text { anos de idade. }\end{array}$ \\
\hline
\end{tabular}




\begin{tabular}{|c|c|c|c|c|}
\hline & Cargo & $\begin{array}{l}\text { Contexto de } \\
\text { atuação }\end{array}$ & Sujeito da formação & Ação \\
\hline 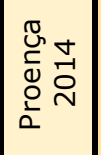 & $\begin{array}{l}\text { Supervisora da } \\
\text { prática } \\
\text { pedagógica }\end{array}$ & $\begin{array}{l}\text { Sistema } \\
\text { municipal de } \\
\text { Ensino }\end{array}$ & $\begin{array}{l}\text { Profissionais da rede } \\
\text { municipal }\end{array}$ & $\begin{array}{l}\text { Promover uma atitude de mediação no contexto } \\
\text { escolar que possa favorecer o processo reflexivo } \\
\text { destes profissionais, considerando as condições } \\
\text { do vivido e seus conflitos (p.94) }\end{array}$ \\
\hline 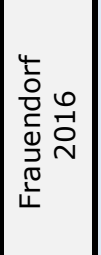 & $\begin{array}{l}\text { Formador de } \\
\text { Formador }\end{array}$ & $\begin{array}{l}\text { Centros de } \\
\text { formação, } \\
\text { escolas, } \\
\text { secretarias } \\
\text { de educação } \\
\text { municipal ou } \\
\text { estadual }\end{array}$ & $\begin{array}{l}\text { Professores, coordenador, } \\
\text { diretores, equipe técnica } \\
\text { da rede municipal/estadual } \\
\text { ed. Infantil e anos iniciais }\end{array}$ & $\begin{array}{l}\text { Mediar ações de formação em serivço (presencial } \\
\text { ou a distância) para contribuir para o } \\
\text { desenvolimento pessoal e profissional de } \\
\text { profissionais da educação por meio de Programa } \\
\text { de formação }\end{array}$ \\
\hline 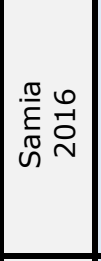 & $\begin{array}{l}\text { Formador de } \\
\text { Formador }\end{array}$ & $\begin{array}{l}\text { Centros de } \\
\text { formação, } \\
\text { escolas, } \\
\text { secretarias } \\
\text { de educação } \\
\text { municipal ou } \\
\text { estadual }\end{array}$ & $\begin{array}{l}\text { Profissionais da Educação } \\
\text { Infantil, em diferentes } \\
\text { funções, quer no âmbito } \\
\text { das universidades, nas } \\
\text { redes públicas ou em } \\
\text { projetos sociais }\end{array}$ & 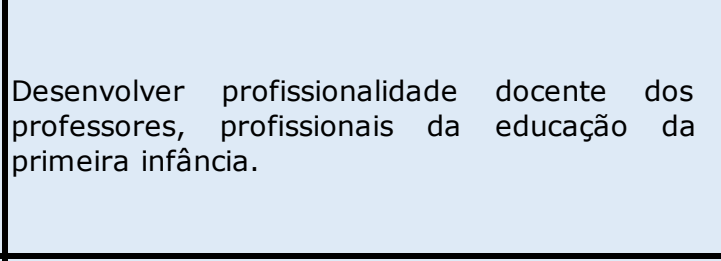 \\
\hline 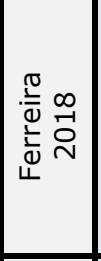 & $\begin{array}{l}\text { Formador de } \\
\text { Formador }\end{array}$ & $\begin{array}{l}\text { Centros de } \\
\text { formação, } \\
\text { escolas, } \\
\text { secretarias } \\
\text { de educação } \\
\text { municipal ou } \\
\text { estadual }\end{array}$ & $\begin{array}{l}\text { Professores, coordenador, } \\
\text { diretores, equipe técnica } \\
\text { da rede municipal/estadual } \\
\text { ed. Infantil e anos iniciais }\end{array}$ & $\begin{array}{l}\text { Mediar ações de formação em serivço (presencial } \\
\text { ou a distância) para contribuir para o } \\
\text { desenvolvimento pessoal e profissional de } \\
\text { profissionais da educação por meio de Programa } \\
\text { de formação }\end{array}$ \\
\hline 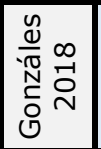 & $\begin{array}{l}\text { Formador de } \\
\text { Formador }\end{array}$ & $\begin{array}{l}\text { Centros de } \\
\text { formação }\end{array}$ & Professores & $\begin{array}{l}\text { Preparação de docentes e responsável pelo } \\
\text { desenho e implantação de programas de } \\
\text { formação continuada }\end{array}$ \\
\hline 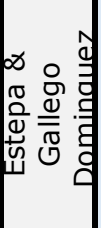 & Assessor & $\begin{array}{l}\text { Centros } \\
\text { Educacionais }\end{array}$ & $\begin{array}{l}\text { Profissionais da educação } \\
\text { Infantil, em diferentes } \\
\text { funções, quer no âmbito } \\
\text { das universidades, nas } \\
\text { redes públicas ou em } \\
\text { projetos sociais. }\end{array}$ & $\begin{array}{l}\text { Preparação de profissionais e responsável pelo } \\
\text { desenho e implantação de programas de } \\
\text { formação continuada }\end{array}$ \\
\hline 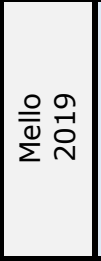 & $\begin{array}{l}\text { Formador de } \\
\text { Formador }\end{array}$ & $\begin{array}{l}\text { Centros de } \\
\text { formação, } \\
\text { escolas, } \\
\text { secretarias } \\
\text { de educação } \\
\text { municipal ou } \\
\text { estadual }\end{array}$ & $\begin{array}{l}\text { Professores, coordenador, } \\
\text { diretores, equipe técnica } \\
\text { da rede municipal/estadual } \\
\text { responsáveis pela } \\
\text { alfabetização }\end{array}$ & $\begin{array}{l}\text { Mediar ações de formação em serivço (presencial } \\
\text { ou a distância) para contribuir para o } \\
\text { desenvolvimento pessoal e profissional de } \\
\text { profissionais da educação por meio de Programa } \\
\text { de formação continuada de profissionais } \\
\text { alfabetizadores }\end{array}$ \\
\hline 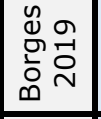 & $\begin{array}{l}\text { Formador de } \\
\text { Formador }\end{array}$ & $\begin{array}{l}\text { Escolas, } \\
\text { centros } \\
\text { educacionais }\end{array}$ & Professores de ed. Infantil & $\begin{array}{l}\text { Desenvolver profissionalidade docente da } \\
\text { educação da primeira infância. }\end{array}$ \\
\hline 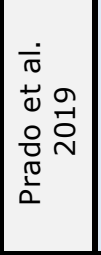 & $\begin{array}{l}\text { Formador de } \\
\text { Formador }\end{array}$ & $\begin{array}{l}\text { Centros de } \\
\text { formação, } \\
\text { escolas, } \\
\text { secretarias } \\
\text { de educação } \\
\text { municipal ou } \\
\text { estadual }\end{array}$ & $\begin{array}{l}\text { Professores, coordenador, } \\
\text { diretores, equipe técnica } \\
\text { da rede municipal/estadual } \\
\text { ed. Infantil e anos iniciais }\end{array}$ & $\begin{array}{l}\text { Mediar ações de formação em serivço (presencial } \\
\text { ou a distância) para contribuir para o } \\
\text { desenvolvimento pessoal e profissional de } \\
\text { profissionais da educação por meio de Programa } \\
\text { de formação e/ou cursos; ações formativas } \\
\text { centradas na escola. }\end{array}$ \\
\hline
\end{tabular}

Ao visualizar o quadro, percebe-se claramente que a inserção de novas referências demandou um trabalho acurado de reinventariar os objetos da coleção, tomando como referência a ideia de inventário da pesquisa como parte do processo de desenvolvimento da 
metodologia narrativa de pesquisa e que tem se configurado em um modo potente de produção de dados. (PRADO, MORAES, 2011; PRADO et al., 2018).

\section{O(a) colecionador(a) e o(a) pesquisador(a) ....}

“[...] por ser sempre uma escolha casual e pessoal, qualquer quinquilharia pode interessar ao colecionador, que vê nesta um resumo do mundo. Entre a dispersão e o vazio, a desordem e a ordem, funda-se uma coleção como promessa de uma perenidade que sempre se dissipa em seu propósito." (Bruna Ferraz)

Encontrar produções acadêmicas que dialoguem com o foco desejado nasce da necessidade de se fazer um mapeamento do conhecimento que já foi produzido sobre o assunto. Nesse agir, o(a) pesquisador(a) vai dialogando com diferentes autores(as) que, por se tornarem importantes referências para ele(a), acabam por legitimar suas ideias assim como por indicar pistas sobre o que precisa ser melhor explicado em sua produção (ANDRE, 2016). Diante dessa necessidade, o(a) colecionador(a) (BENJAMIN, 2018), tal qual o(a) pesquisador(a), percorre labirintos por vezes escuros e sombrios, formados pelos corredores de bibliotecas, livrarias e sebos; navega por diferentes redes, por vezes deixando-se perder entre multidões de arquivos, a fim de garimpar aquilo que lhe é mais precioso. Para cada achado, ele(a) irá se debruçar na minúcia da inspeção - por meio da leitura dos resumos, palavras-chaves, ano da produção - para então capturar e guardar o material encontrado. Aos poucos a coleção vai ganhando corpo, vai sendo organizada por critérios distintos e significativos ao pesquisador(a)colecionador(a) como por exemplo: artigos, teses e dissertações, capítulos de livros; autor; ano... e toda aquela desordem inicial com a qual se deparou ganha outros sentidos e contornos. Enfim, "entre a ordem e a desordem, há um movimento contínuo, uma organização em devir perene, jamais atingível (Krüger, 2014, p.72)."

Excepcionalmente no ano de 2020 , devido à pandemia da Covid- $19^{4}$, os espaços de pesquisa ficaram reduzidos à WEB durante alguns meses, uma vez que as bibliotecas e livrarias foram fechadas em função do decreto de isolamento social, que ocorreu nas cidades de nosso país. Assim, entendemos que a coleção aqui apresentada é por certo inacabada e que poderá ser mais uma vez revisitada para ser complementada com documentos e

\footnotetext{
${ }^{4}$ A COVID-19 é uma doença causada pelo coronavírus SARS-CoV-2, que apresenta um quadro clínico que varia de infecções assintomáticas a quadros respiratórios graves. https://coronavirus.saude.gov.br/sobre-adoenca. Acesso em 11/07/2020.
} 
preciosidades, talvez escondidos nas prateleiras de alguma biblioteca, livraria ou sebo, aguardando o momento certo para serem encontrados.

Essa sensação da coleção de produções acadêmicas referente ao foco da pesquisa estar inacabada também pode encontrar explicação na sempre insatisfação do(a) colecionador(a)-pesquisador(a), que imagina sua coleção sempre incompleta.

No que se refere ao colecionador, sua coleção nunca está completa; e se lhe falta uma única peça, tudo o que colecionou não passará de uma obra fragmentária, tal como são as coisas desde o princípio para a alegoria (BENJAMIN, 2018, p.358).

Frente a esse contexto, realidade e dificuldades, a coleção atual foi organizada em cinco conjuntos: artigos; dissertações e teses; livro/capítulo de livro; publicações e outros. Sendo que no conjunto artigos há 3 subconjuntos: formador de formador (1994-2012/ 20132019); Pesquisa narrativa; Walter Benjamin.

No total foram encontradas 106 produções que se relacionam direta ou indiretamente ao eixo formador de formadores, no recorte pretendido, durante o período de 1994 a 2019. Para nosso estudo nos concentraremos nos artigos, teses e dissertações publicados e interpretados no período de 2013 a 2019. No entanto, optamos por incluir na versão atualizada do quadro 2 a primeira referência encontrada ao termo - formador de formador - nessa nova pesquisa, que data de 1998, e foi feita por Jacky Beillerot no livro: La formacion de formadores (entre la teoria y la prática), Facultad de Filosofia y Letras - UBA - Ediciones Novedades Educativas, Formacion de Formadores - serie Los Documentos 1, $1^{\mathrm{a}}$. Edicion, julho, 1998.

Esse recorte do ano se justifica por abranger o limiar na acepção benjaminiana entre o início da pesquisa de mestrado "A voz de uma professora-formadora que se inventa e reinventa a partir da/com/na escola" (2013) até início da pesquisa de doutorado "De estelas a constelação: uma comunidade de práticas formativas de formadoras de formadoras". Nesse percurso de escavar os bancos de dados combinamos ações planejadas como: definição da área de conhecimento: educação e tema da pesquisa: formação continuada - formador de formador; delimitação de datas da pesquisa: 2013 a 2019 que já foi anteriormente justificada; com ações inesperadas e que abrissem espaços para o acaso para nos perdermos na escuridão da floresta (MATOS 1990), para então seguirmos pistas e vestígios que nos levassem a acreditar em nossos sentidos e experiências na produção de conhecimento. Um caminhar que não se opõe à cientifização do conhecimento, mas que desconfia dessa forma que quer ser válida em qualquer tempo e lugar, independente dos sujeitos e locais. Um caminhar que não nos deixa iludir com o aparato da técnica e que, por isso, traz riscos de queda no abismo, ou mesmo de desestabilizar o padrão, como nos provoca Krenak (2020, p.57). 
Ao trilhar o caminho para procurar novos artefatos para coleção de produções acadêmicas, observamos as palavras-chaves mais recorrentes em artigos de sites de periódicos nacionais; repositórios de teses e dissertações; anais de eventos como ANPED. bem como a tradução para o inglês que se tornaram como bússolas para orientar a nossa busca futura.

De posse dessa lista navegamos por diferentes sites como: BDTD - Biblioteca Digital Brasileira de Teses e Dissertações, Repositório da Produção Científica e Intelectual da Unicamp, Site de teses e dissertações e periódicos da Capes, SCIELO, Repositório da Universidade de Lisboa, Repositório da Universidade de Barcelona, Repositório da Universidade de Buenos Aires, EDUBASE, Redalyc, Dialnet, Google Acadêmico, Centro de Informação e Biblioteca em Educação (Cibec). A necessidade de circular por tantas fontes de informação levou em conta a experiência vivida e rememorada no processo de levantamento de literatura especializada realizado no ano de 2014, relativo à dificuldade em encontrar produções acadêmicas relacionadas ao profissional que atua em programas de formação continuada e que forma novos formadores. Obviamente que algumas dessas palavras-chaves e fontes de informação foram deixadas de lado no processo, seja por oferecerem poucas contribuições ao que se pretendia no momento da pesquisa, seja por não encontrar o material desejado ou mesmo por estar de certa forma desatualizado nos repositórios de algumas universidades.

Durante o processo de busca, por exemplo, na Biblioteca Digital Brasileira de Teses e Dissertações (BDTD) notamos que algumas produções da Faculdade de Educação/Unicamp, a partir do ano de 2015, não eram relacionadas ao filtrar por palavrachave, ano ou mesmo por autor. A pista que nos fez observar isso foi a ausência da dissertação de mestrado: "A voz de uma professora-formadora que se inventa e reinventa a partir da/com/na escola" que traz como uma das palavras-chaves: formador de formador, ano 2016, autor: Frauendorf. Procuramos, então, por outros trabalhos acadêmicos publicados nos anos de 2015, 2016, 2017, 2018 pelo grupo de pesquisa GEPEC- FE-Unicamp e do qual fazemos parte, e não encontramos também. Nossa suspeita é a de que, com o lançamento do Repositório Institucional da Unicamp em 2015, que veio substituir a Biblioteca Digital da Universidade, as produções publicadas durante os anos de 2015 até 2018 não haviam sido incorporadas ao BDTD naquele momento. Diante disso, optamos por descartar essa fonte de informação, pois o mesmo poderia ocorrer com outros repositórios. Selecionamos os seguintes bancos de dados para concentrar nosso levantamento bibliográfico: CAPES; Repositório Universidade de Lisboa; Repositório Universidade de Barcelona; EDUBASE; Centro de Informação e Biblioteca em Educação (Cibec); Google Acadêmico. 
Nesse exemplo é importante iluminar o fato de que a desconfiança da precisão e da confiabilidade dos achados no banco em questão nos deslocou da trilha por algum tempo e nos fez duvidar de nossos sentidos e de nossas experiências vividas, depositando a causa do problema - não encontrar as pesquisas desejadas - no sujeito e não no repositório.

Após esse desvio de percurso, retomamos a leitura e exploração das produções achadas e fizemos uma seleção inaugural de publicações que atendiam ao recorte definido e arquivamos em repositório da pesquisadora/autora1 em que os documentos eram salvos da seguinte forma: ANO_SOBRENOME AUTOR_TÍTULO. Também pudemos perceber, nesse exercício, que alguns termos não contribuíam para localizar as produções nos bancos de dados o que nos permitiu reduzir bastante a lista e privilegiar palavras-chaves que oferecessem um melhor retorno para as buscas como: formação de formador (20 publicações); professor-formador (9 publicações); formação continuada (2 publicações); formação permanente (1 publicação). A fim de refinar a pesquisa descartamos as publicações referentes à ideia do(a) formador(a) de formador(a) na Universidade, no contexto do ensino superior e formador(a) de professor(a), ou que não fosse relacionado ao campo da educação, por não se relacionar ao recorte pretendido. Esse foi um primeiro refinamento que nos levou a um número mais limitado de produções. Ao peneirar os achados, quando restaram algumas dúvidas sobre a inclusão ou não de determinada pesquisa ou artigo na coleção, resolvemos por meio da leitura e estudo dos resumos. Quando necessário fizemos uma leitura mais inspecional, percorrendo alguns trechos da produção para, com isso, ter uma visão mais macro do texto em que fosse possível verificar o contexto de atuação do formador e excluir o que não comungava com o recorte desejado.

Toda a coleção foi reorganizada em uma planilha de EXCEL dividida em duas abas. Uma intitulada: 2013 a 2019 com as colunas BANCO DE DADOS/ AUTOR/ TíTULO/ ANO/ PUBLICAÇÃO/ TIPO (artigo, dissertação, tese) / RESUMO. E uma segunda aba cujo título é anterior a 2013, que mantém o mesmo critério de definição das colunas. A interpretação das produções de 2013 a 2019 forneceu os dados necessários para complementar e atualizar o quadro 2: Panorama atual da variação de denominação de cargo, contexto de formação, sujeito da formação e atuação do formador de formador (2020).

\section{Resultados e Discussão}

A apreciação e estudo da coleção de publicações referente ao período de 2013 a 2019 nos permitiu identificar 33 publicações relacionadas ao recorte: profissional em programas de formação continuada, responsável por formar novos(as) formadores(as) 
(coordenadores/as pedagógicos/as e equipe técnica de secretarias de educação), atuando em escolas, centros de formação, secretarias de educação, diretorias ou regionais de ensino. Foram encontrados 15 artigos publicados em periódicos variados; 4 artigos publicados em anais de seminários nacionais e internacionais; 10 dissertações de mestrado; 1 capítulo de E-book; 1 capítulo de livro e apenas 2 teses de doutorado sendo que uma delas, Ferreira (2013), já fazia parte da coleção de 2014. A tese mais recente: Singularidades nas experiências de formadores da educação infantil (SAMIA, 2016, p.7), revela não só o que constitui o processo de formação de formadores de Educação Infantil como também contribui para se pensar sobre a formação como um processo singular em que a parceria entre formador e sujeito da formação é um eixo importante na relação de ensino e de aprendizagem, pautada em experiências significativas a todos os atores envolvidos num processo formativo, reforçando a ideia inicial que já trazíamos em nossa bagagem.

[...] Ao investigar o que dá contornos próprios à formação de formadores que atuam neste segmento [Educação Infantil], buscou-se, por meio das narrativas orais, compreender que experiências tiveram especial significado nos seus percursos formativos, ou seja, aquelas que contribuíram na constituição do ser formador e, dessa forma, colaborar tanto para os estudos sobre formação, quanto para o estatuto específico da profissão, relativo ao processo de profissionalização[...] A pesquisa de campo envolveu a escuta de formadores, a partir de Rodas de Conversa - a roda de formadores e a roda de observação - e Entrevistas com Especialistas, que compuseram o quadro metodológico. Na grande roda de diálogo que foi o percurso investigativo, emergiram com força as ideias de formação, como um processo singular de tornar-se o que se é; do formador como um parceiro na aventura de conduzir alguém até si mesmo; da potência de uma formação pautada em experiências de naturezas diversas, representada pela ciranda de experiências; da emergência da escuta de crianças como dispositivo de formação, para a consolidação de uma relação alteritária entre adulto e criança. Emergiu ainda a força do diálogo, das experiências e das narrativas, como potentes condutoras de percursos investigativos e formativos[..]

A revisão bibliográfica feita por Samia (2016) e incorporada como anexo em sua tese contribuiu bastante para o processo de levantamento de bibliografia correspondente à temática sugerida nesse artigo, muito embora em sua tese a pesquisadora inclua no levantamento produções sobre o formador de formador que atua na universidade e que, em nosso caso, não é contemplado.

A outra produção encontrada é uma dissertação de mestrado profissional defendida em 2018, na Pontifícia Universidade Católica de São Paulo por Rodinilson Luiz Ferreira intitulada "As significações do formador de formadores sobre sua atividade profissional no âmbito da formação continuada em serviço". A investigação procura compreender as significações que o "formador de formadores" constrói sobre sua atividade profissional no âmbito da formação continuada em serviço, antes, durante e depois da participação em um programa de formação no âmbito público em parceria com setor privado. Ferreira entende que, esses profissionais se formam em serviço e no contexto de trabalho, pois é na sua 
atividade profissional que enfrenta e resolve problemas, desenvolve e aperfeiçoa procedimentos, bem como lança mão de estratégias de trabalho ajustadas à realidade e ao grupo com o qual está atuando. Para o autor (2018) "o desenvolvimento profissional [do formador de formador] acontece na prática, a partir da reflexão sobre a prática para a mudança da prática (p.113)". A associação do papel do(a) formador(a) de formadores(as) como agente de mudança da prática do sujeito em formação, como aquele que garante a formação do outro, é bem presente no texto.

Em relação aos artigos encontrados há três publicações mais recentes de 2019:

BORGES, Simoni P.- O papel do formador no processo de formação continuada: formadores ou informadores. O artigo objetiva discutir a importância do formador no processo, de modo a compreender o papel do formador no contexto da formação continuada de professores.

MELLO, Angela R.C - Reflexões de uma experiência enquanto formadora regional no contexto do Pnaic em Mato Grosso, no qual a autora apresenta aspectos de uma experiência realizada enquanto Formadora Regional do Pacto Nacional pela Alfabetização na Idade Certa, edição final de 2017/2018, coordenado pelo Programa de Pós-graduação em Educação, da Universidade Federal de Mato Grosso, Campus Universitário de Rondonópolis.

PRADO, Guilherme do Val Toledo; PROENÇA Heloísa Helena Dias Martins; MAGRI, Lucianna de Melo Munhoz; FRAUENDORF, Renata Barroso de Siqueira - "Formação de professores em narrativas singulares". O capítulo faz parte do e book: Formação permanente de professores: experiências ibero-americanas organizado por Francisco Imbernon; Alexandre Shigunov Neto; Ivan Fortunato. Os autores narram as trajetórias de três pesquisadoras que atuam e investigam a formação continuada de professores e demais profissionais da instituição escolar. Como formadoras partilham o princípio de que é preciso considerar o percurso de construção de autonomia dos sujeitos no processo formativo, reafirmando a ideia de uma formação continuada dos profissionais da educação amparada em práticas que considerem o cotidiano, suas necessidades e os sujeitos em interação.

E duas de 2018:

GONZÁLEZ, María Paz - El estudio del formador latinoamericano: un campo de investigación 'en construcción'. Nesse artigo a autora apresenta uma revisão sistemática da literatura latino-americana sobre o formador e conclui que o formador, como objeto de pesquisa na América Latina, é um campo com escasso avanço teórico e empírico, isto é, se encontra em 'processo de construção', muito embora foque apenas no formador de professor.

MURILO ESTEPA Paulino, GALLEGO-DOMINGUEZ, Carmem - Condiciones de desarrollo profesional del tecnico docente Dominicano como asesor pedagogico. $O$ artigo 
aborda a formação de assessores externos aos centros educacionais como um fator determinante em qualquer etapa de desenvolvimento profissional com vistas à melhora da instituição. Discutem especificamente a atuação de técnicos na República Dominicana e o quanto ainda é presente a ideia de formador como o sujeito que supervisiona e inspeciona os profissionais da instituição.

\section{Considerações finais}

Toda existência humana é uma vida em busca de uma narrativa.

Richard Kearney

Todo este estudo e seleção de literatura referente à temática formador(a) de formadores(as) indicia a necessidade de se ampliar a investigação sobre esse profissional da educação não com o propósito de delimitar o termo (MARCELO GARCIA, 1999; FERREIRA, 2018), que é tão abrangente como revelado neste texto, mas fundamentalmente para se conhecer mais sobre esse ofício - de certa forma recente, considerando a história da educação - ; as necessidades dos profissionais, o modo de atuar e produzir conhecimento junto a outros formadores(as); bem como aproximar-se daquilo que o(a) mobiliza em seu fazer experiencial. Nesse aprofundamento sobre a temática e no recorte das parcerias públicoprivadas, é possível afirmar que, em grande parte das vezes, em nosso país, o(a) formador(a) de formadores(as) trabalha em contexto bem específico - geralmente é externo(a) à rede de ensino - , firma relações entre pares com maior ou menor experiência pessoal e/ou na prática docente ou de gestão, e atua com um público frequentemente convocado pelas secretarias de ensino, podendo ser agentes de educação, professores (as), coordenadores(as) pedagógicos(as), diretores(as), ou técnicos(as) de secretaria (FRAUENDORF, 2016; SAMIA, 2016; ESTEPA \& GALLEGO-DOMINGUEZ, 2018; FERREIRA, 2018; MELLO, 2019; PRADO et al., 2019). A ampliação do público a ser envolvido nos processos de formação continuada também é um forte indicativo do quanto nos últimos anos ganhou força a ideia da organização da escola como espaço de colaboração, do coletivo, enfraquecendo (não excluindo) a representação social do professor como único responsável pelo sucesso ou fracasso do processo de aprendizagem dos estudantes (GASTALDI, 2013), uma vez que ainda é muito presente nos discursos que circulam em nossa sociedade a culpabilização do docente em relação às situações de fracasso escolar.

Uma outra especificidade referente à formação profissional do(a) formador(a) de formadores(as), que difere do contexto da universidade e enunciado na literatura, é a carência de cursos de graduação, pós graduação e/ou formação continuada, o que faz com que, em 
geral, esses(as) profissionais se formem em serviço e entre pares (BEILLEROT, 1998; VAILLANT, 2013; FRAUENDORF, 2016; SAMIA, 2016; ESTEPA \& GALLEGO-DOMINGUEZ, 2018; GONZÁLEZ, 2018; FERREIRA, 2018; MELLO, 2019).

Já no âmbito de programas de formação continuada em serviço o(a) formador(a) de formadores(as) atua diretamente com profissionais - adultos formados, ou seja, o vínculo se dá ancorado na experiência profissional de quem já está no contexto da instituição seja na escola (docentes, gestores) ou indiretamente, no papel de técnicos, via secretarias de educação, regionais, diretorias ou núcleos de ensino (ESTEPA \& GALLEGO-DOMINGUEZ, 2018; FERREIRA, 2018; MELLO, 2019; PRADO et al., 2019). Enfim, é um(a) profissional da formação continuada que tem o saber, a experiência de vida e o outro como matéria prima de seu ofício. Um saber que pode nascer do diálogo, das experiências vividas, dos lampejos de memórias individuais e coletivas e do ato de partilha de narrativas (BENJAMIN, 1987; SAMIA, 2016; PRADO et al., 2019). Um saber, por outro lado, relacionado ao poder, porque formadores(as) de formadores(as), por mais que prestem um serviço de caráter público, são vistos(as) como representantes da organização de iniciativa privada e demais parceiros que "oferecem" as formações para as redes de ensino. Nesse sentido, ocupam o lugar, mesmo não desejando ou tendo consciência, daquele que tem maior legitimidade do saber, trazendo, impondo ou mesmo reiterando por vezes a narrativa de grupos dominantes na sociedade. Beillerot (1998, p. 93) afirma que, "Las sociedades definen qué saberes son legítimos. En la legitimidad del saber las luchas son a veces muy fuertes y esto se a y rodea la creacion de uma nueva disciplina."

Nas palavras de Gonzales (2018, p.37) "o formador como objeto de investigação na América Latina é um campo com escasso avanço teórico e empírico, trata-se de um campo em construção". As novas leituras realizadas do material que forma a coleção, muito embora indiquem que há muito o que se investigar ainda, já apontam caminhos e saberes mais recentes construídos sobre o(a) formador(a) de formadores(as) aqui apontados (SAMIA, 2016; FRAUENDORF, 2016; ESTEPA \& GALLEGO-DOMINGUEZ, 2018; FERREIRA, 2018; GONZALES, 2018; BORGES, 2019; MELLO, 2019; PRADO et al., 2019).

Ao narrar como fomos compondo a coleção de produções acadêmicas pretendemos contribuir não só com as discussões e reflexões sobre o eixo formador(a) de formadores(as), mas também apresentar um modo outro de buscar, selecionar e organizar a literatura de determinada área, não mais eficiente nem tampouco mais infalível do que se apresenta quase que exclusivamente no momento, apenas diferente. Propusemo-nos um movimento que segue um rumo contrário ao praticado atualmente em que a seleção geralmente obedece a 
padrões orientados por indexadores e algoritmos, atendendo ao par ciência/técnica (LARROSA, 2015) e que praticamente exclui o sujeito da experiência.

Na trajetória, nos questionamos se seria essa a única forma possível de se relacionar com as produções, como também se haveria algo mais coerente com uma investigação que tem a metodologia narrativa em sua radicalidade como princípio (PRADO et al., 2015). Ousamos ao tentar percorrer uma trilha em que sentidos, experiências e memória significassem e apoiassem nossas escolhas para além do caminho orientado por uma racionalidade técnica (MATOS, 1990), que nos leva a uma perspectiva mais canônica, positivista. Vimos ser possível e interessante perseguir caminhos ora desconhecidos, esbarrar-se em dificuldades, deparar-se com obstáculos, perder-se para encontrar-se, alegrar-se com achados - pequenos que sejam - guardando-os e alimentando uma coleção de saber e de literatura. Vimos ser possível construir um saber experiencial numa tarefa que por vezes é realizada burocraticamente porque não envolve a paixão do(a) colecionador(a). Como pesquisador(a)colecionador(a), percebemos valor ao colocar em destaque a sensibilidade do leitor, seus conhecimentos de mundo, suas possibilidades de tecer relações entre as obras, autores, contextos, experiências, lembranças e esquecimentos. Muito embora seja bem mais subjetivo, isso não há dúvida, não é menos importante, ou menos válido.

\section{Referências}

ANDRE, Marli. A Formação do Pesquisador da Prática Pedagógica. Plurais Revista Multidisciplinar. Salvador, v.1, n. 1, p. 30-41, jan./abr. 2016.

BEILLEROT, Jacky. La formacion de formadores (entre la teoria y la prática). Facultad de Filosofia y Letras - UBA - Ediciones Novedades Educativas, Formacion de Formadores serie Los Documentos 1, $1^{\text {a }}$. Edicion, julho, 1998.

BENJAMIN, Walter. Obras escolhidas II. Rua de mão única SP: Editora Brasiliense, 1987.

BENJAMIN, Walter. O colecionador. In Passagens. Tradução de Irene Aron e Cleonice Paes Barreto Mourão. Belo Horizonte: Ed. UFMG, 2018.

BORGES, Simoni P. O papel do formador no processo de formação continuada: formadores ou informadores. Research, Society and Development, v. 9, n. 3, e04932262. https://doi.org/10.33448/rsd-v9i3.2262

BRAGANÇA, Inês Ferreira de Souza. Pesquisa-formação e histórias de vida de professoras brasileiras e portuguesas: reflexões sobre tessituras teórico-metodológicas. Revista @mbienteeducação, São Paulo, v. 2, n. 2, p. 37-48, ago./dez. 2009. 
CUNHA, Renata.C.O.B. Pelas telas, pelas janelas: a coordenação pedagógica e a formação de professores/as nas escolas. 2006. 288 f. Tese (Doutorado) - Curso de Doutorado em Educação, Ensino e Práticas Culturais, Unicamp, Campinas, 2006.

ESTEPA, Paulino Murillo; GALLEGO-DOMíNGUEZ, Carmen. Condiciones de desarrollo profesional del técnico docente Dominicano como asesor pedagógico. Revista de Investigación en Educación, [S.I.], v. 16, n. 1, p. 51-67, abr. 2018. ISSN 2172-3427. Disponible en: <http://reined.webs.uvigo.es/index.php/reined/article/view/312>. Acesso: 06 oct. 2020.

FERREIRA, Claudia R. Labirinto de perguntas: reflexões sobre a formação de professores na e a partir da escola. 2013. 279 f. Tese (Doutorado) - Curso de Doutorado em Educação, Ensino e Práticas Culturais, Unicamp, Campinas, 2013.

FERREIRA, Rodnilson Luiz. As significações do formador de formadores sobre a sua atividade profissional no âmbito da formação continuada em serviço. 2018. $166 \mathrm{f}$. Dissertação (Mestrado) - Curso de Educação, Pontifícia Universidade Católica de São Paulo, São Paulo, 2018. Disponível: https://tede2.pucsp.br/bitstream/handle/21923/2/Rodnilson\%20Luiz\%20Ferreira. pdf. Acesso em: 09 maio 2020.

FRAUENDORF, Renata B. S. A voz de uma professora - formadora que se inventa e reinventa a partir da/com/na escola. Dissertação (Mestrado) - Curso de Mestrado em Educação, Campinas, SP: Unicamp, 2016. $170 f$.

FRAUENDORF, Renata B. S; PRADO, Guilherme do Val T. Comunidade virtual de práticas de formador de formadores: um convite à escrita de narrativas de experiências vividas. Educar em Revista, [S.I.], maio 2021. ISSN 1984-0411. Disponível em: <https://revistas.ufpr.br/educar/article/view/75530>. Acesso em: 23 jun. 2021.

GAGNEBIN, Jeanne Marie. A Criança no Limiar do Labirinto - História e Narração em Walter Benjamin. São Paulo: Perspectiva, 2013. 5a reimpr. da 2. ed de 1999.

GALZERANI, Maria Carolina B. A produção de saberes históricos escolares: o lugar das memórias. In: O Historiador e seu tempo. Unesp, 2008.

GASTALDI, Maria Virginia. Formação continuada na Educação Infantil: possibilidades e desafios na perspectiva do formador. 2012. 157 f. Dissertação (Mestrado) - Curso de Mestrado em Educação, Pontifícia Universidade Católica de São Paulo, São Paulo, 2012.

GONZÁLEZ, María Paz. El estudio del formador latinoamericano: un campo de investigación 'en construcción', Magis, Revista Internacional de Investigación en Educación, 10 (21), 35-54. DOI: 10.11144/Javeriana.m10-21.eflc, 2018.

GOUVEIA, Beatriz. B. Formação dos coordenadores pedagógicos em Boa Vista do Tupim/BA: uma experiência colaborativa, o fio por trás das missangas. 2012. $171 \mathrm{f}$. Dissertação (Mestrado) - Curso de Mestrado em Educação, Psicologia da Educação, Pontifícia Universidade Católica de São Paulo, São Paulo, 2012.

IMBERNON, Francisco. Formação Docente e Profissional: formar-se para a mudança e a incerteza. 9. ed. São Paulo: Cortez, 2011. 14 v. Coleção Questões da nossa época. 
KITCHENHAM, Barbara; CHARTERS, Stuart. Guidelines for performing Systematic Literature Reviews in Software Engineering, Department of Computer Science University of Durham, Durham, UK, 2007.

KRENAK, Ailton. Ideias para Adiar o Fim do Mundo. Companhia das Letras. São Paulo, $2^{\mathrm{a}}$.edição, 2020.

KRUGER, Constance von. A coleção - um gesto poético: uma leitura benjaminiana sobre o colecionismo. Cadernos Benjaminianos , v. 8, p. 71-78, 2014.

LARROSA, Jorge. Tremores: escritos sobre experiência. Belo Horizonte: Autêntica, 2015.

MARCELO GARCIA, Carlos. La Formación de los Formadores como espacio de trabajo e investigación: dos ejemplos. XXI Revista de Educación, Huelva, v. 01, p.33-57, 1999. Anual. ISSN-e: 1575-0345. Disponível em: http://rabida.uhu.es/dspace/handle/10272/3349 Acesso em: 06 out. 2020.

MATOS, Olgária Chain Féres. Desejo de evidência, desejo de vidência: Walter Benjamin Artepensamento, 1990. Disponível em: https://artepensamento.com.br/item/desejo-deevidencia-desejo-de-videncia-walter-benjamin/ . Acesso em:06 out.2020

MELLO, Angela R.C. Reflexões de uma experiência enquanto formadora regional no contexto do Pnaic em Mato Grosso, Revista Ibero-Americana de Estudos em Educação, Araraquara, v. 14, n. 3, p. 1229-1244, jul./set., 2019. e-ISSN: 1982-5587. DOI: 10.21723/riaee.v14i3.11510.

NOVOA, Antônio. Formação de professores e trabalho pedagógico. Lisboa: Educa, 2002. 88 p. Disponível em: <repositorio.ul.pt/bitstream/10451/3703/1/formprof.pdf> Acesso em: 10 jan. 2016.

PERRENOUD, P. A. Práticas Pedagógicas, profissão docente e formação: perspectivas sociológicas. 2. ed. Lisboa: Publicações Dom Quixote Instituto de Inovação Educacional, 1997.

PIERINI, Adriana Stella. Os espaços de conversa: a orientadora pedagógica e a formação com o cotidiano - com prosa e com verso, a experiência de ser ex de si. 2014. $339 \mathrm{f}$. Tese (Doutorado) - Curso de Doutorado em Educação, Psicologia Educacional, Unicamp, Campinas, 2014.

PRADO, Guilherme do Val T; MORAIS, Jaqueline de Fátima S. Inventário - organizando os achados de uma pesquisa. EntreVer, Florianópolis, v. 01, n. 01, pp. 137-154, 2011.

PRADO, Guilherme Do Val. T.; FRAUENDORF, Renata B. Siqueira.; CHAUTZ, Grace C. Chaves Buldrin. Inventário de pesquisa: uma possibilidade de organização de dados da investigação. Revista Brasileira de Pesquisa (Auto)biográfica, v. 3, n. 8, p. 532-547, 14 set. 2018.

PRADO, Guilherme do Val Toledo; PROENÇA, Heloisa Helena Dias Martins; FRAUENDORF, Renata Barroso de Siqueira; MUNHOZ, Lucianna Magri de Melo. Formação de professores em narrativas singulares. In: Formação permanente de professores: experiências iberoamericanas. Francisco Imbernon; Alexandre Shigunov Neto; Ivan Fortunato; (org.) pp.239. Edições Hipótese, 2019. 
PROENÇA, Heloisa Dias M. Supervisão da Prática Pedagógica: percursos formativos em parceria e diálogo com os profissionais da educação. 2014. 316 f. Dissertação (Mestrado) Curso de Mestrado em Educação, Ensino e Práticas Culturais, Unicamp, Campinas, 2014.

SAMIA, Mônica M. Diálogos formativos: singularidades nas experiências de formadores da educação infantil. - 2016. 245 f. Tese (Doutorado) - Curso de Doutorado em Educação, Currículo e (IN) formação, Faculdade de Educação da Universidade Federal da Bahia, Salvador, 2016.

STATONATO, Soraia C. A formação dos formadores: uma análise do processo formativo. 2010. 106 f. Dissertação (Mestrado) - Curso de Mestrado em Educação, Universidade Cidade de São Paulo, São Paulo, 2010.

SOLIGO, Rosaura. Quem forma quem? Instituições de sujeitos. 2007. 212 f. Dissertação (Mestrado) - Curso de Mestrado em Educação, Ensino e Práticas Culturais, Unicamp, Campinas, 2007.

VAILLANT, Denise. Formação de Formadores: Estado da Prática. Preal, Online, v. 25, n. 25, p.1-60, out. $2003 . \quad$ Disponível em: <http://www.preal.org/BibliotecaDes.asp?id=36\&Camino;=> Acesso em: 28 dez. 2015. 